\title{
Detection of Pathogenic Microorganisms from Burn Patients Admitted in Tertiary Medical College Hospital and Their Antimicrobial Patterns
}

\author{
Kaniz Fatema ${ }^{1 *}$, Shahina Sultana ${ }^{1,2}$, Mohammad Hedayet Ali², Tanzina Akter ${ }^{1,3}$, \\ Khadiza-Tul-Kobra' ${ }^{1,3}$, Shiful Islam ${ }^{1}$ \\ ${ }^{1}$ Department of Microbiology, Primeasia University, Dhaka, Bangladesh \\ ${ }^{2}$ Sheikh Hasina National Institute of Burn and Plastic Surgery, Dhaka, Bangladesh \\ ${ }^{3}$ Environmental Biotechnology Division, National Institute of Biotechnology, Dhaka, Bangladesh \\ Email: ${ }^{\star}$ kaniz_0309@yahoo.com
}

How to cite this paper: Fatema, K., Sultana, S., Ali, M.H., Akter, T., Khadiza-Tul-Kobra and Islam, S. (2021) Detection of Pathogenic Microorganisms from Burn Patients Admitted in Tertiary Medical College Hospital and Their Antimicrobial Patterns. Open Journal of Medical Microbiology, 11, 58-67.

https://doi.org/10.4236/ojmm.2021.111005

Received: November 11, 2020

Accepted: March 27, 2021

Published: March 30, 2021

Copyright $\odot 2021$ by author(s) and Scientific Research Publishing Inc. This work is licensed under the Creative Commons Attribution International License (CC BY 4.0).

http://creativecommons.org/licenses/by/4.0/ (c) (i) Open Access

\begin{abstract}
Object: To isolate and identify the microorganisms from the burn patients admitted to the National Institute of Burn and Plastic Surgery Unit in Tertiary Medical College Hospital, Bangladesh. A total number of fifty wound surface swab samples of first and second-degree burn patients were collected and the microbial analysis as well as the study of antibacterial susceptibility was conducted. The study showed the bacterial isolates were found. 45 (90\%) of wound swab were positive among 50 and only 5 samples (10\%) were negative in bacterial growth, which presented invasive burn wound infection from both sex age groups marked 12 - 60 years. The total viable count TVC-11651 $\mathrm{CFU} /$ plate was found and the highest amount in the second-degree burn patients. The results showed that Pseudomonas aeruginosa was common in all positive samples $6636 \mathrm{CFU} /$ plate (57\%) followed by Staphylococcus aureus $4070 \mathrm{CFU} /$ plate (35\%), Klebsiella spp. $450 \mathrm{CFU} /$ plate (5\%), Proteus spp. 243 $\mathrm{CFU} /$ plate (2\%), and E. coli $162 \mathrm{CFU} /$ plate (1\%). Most of the pathogens were found to be drug-resistant while several isolates were noted to be multi-drug resistant. The growth of multidrug-resistant organisms should be considered as a serious risk factor in a burn unit. Aggressive infection control measures should be applied to limit the emergence and spread of multidrug-resistant pathogens.
\end{abstract}

\section{Keywords}

Pseudomonas aeruginosa, Antimicrobial Activity, Burn Wounds, Microorganisms 


\section{Introduction}

Burn injury is one of the most common and devastating forms of trauma and a major public health concern all around the world. The burn patients have a unique predisposition to different infections which are linked to impaired resistance from disruption of the skin's mechanical integrity and generalized immune suppression. The skin barrier is replaced by a protein-rich, vascular environment that provides a favorable niche for microbial colonization and proliferation by one or more sepsis of microorganisms anywhere and becomes better placed to cause damage to the host sterile tissues. A wound can be infected by a variety ranging from bacteria to fungus and parasites mostly gram-positive and gram-negative microorganisms. Additionally, the migration of the immune cell is hampered, which contributes to the septic process [1]-[6]. It has been estimated that $75 \%$ of all deaths following thermal injuries are related to infection. Initially, the burned area is considered free of major microbial contamination. However, gram-positive bacteria in the depths of sweat glands and hair follicles may survive the heat of initial injury and unless topical antimicrobial agents are applied, these bacteria heavily colonize the wounds within the first $48 \mathrm{~h}$ post-injury [7] [8] [9]. Although any organisms is a potential pathogen in burned patients, coagulase-negative Staphylococci and $S$. aureus were the most common gram-positive pathogens and Pseudomonas aeruginosa, E. coli, and K. pneumonae and Proteus vulgaris were the common gram-negative microorganisms [10] [11]. Thus, the current research study aimed to determine the microorganisms and their susceptibility patterns which were isolated from burn wounds of patients at the National Institute of Burning and Plastic Surgery Unit of Dhaka Medical College Hospital Dhaka. Burns is one of the most common traumas. There are about 2 million fires each year, 1.2 million people with burn injuries, 100,000 hospitalizations, and 5000 patients die from related complications [12]. Nosocomial infections (NI) are common in burn patients due to the typical features of the disease: loss of the first line of defense against microbial invasion; the presence of devitalized, a vascularized tissue that provides a favorable environment for microbial growth; alterations in the specific and nonspecific components of the immune system; gastrointestinal translocation; and extended hospitalization and multiple invasive diagnostic and therapeutic procedures [13] [14]. In recent years, drug resistance to human pathogenic bacteria is being commonly reported from all over the world. However, the situation is alarming in developing as well as developed countries due to indiscriminate use of antibiotics [15], although pharmaceutical industries have produced a large number of newer antibiotics in the last three decades. The reason behind this is that microorganisms are becoming resistant to both older and newer antibiotics [16]. Besides, bacteria have the genetic ability to transmit and acquire resistance to drugs which are utilized as therapeutic agents and transferring the resistance from one bacterium to another. Antibiotics provide the main basis for the therapy of microbial infections. Since the discovery of these antibiotics and their uses 
as chemotherapeutic agents, there was a belief in the medical fraternity that this would lead to the eventual eradication of infectious diseases [17]. However, overuses of antibiotics have become the major factor for the emergence dissemination of multidrug-resistant strains of several groups of microorganisms. Resistant bacteria impact public health in such a way that it increases morbidity and mortality from treatment failures and increases healthcare cost as newer and more expensive antibiotics are needed to treat infections [18]. Resistant bacteria are emerging worldwide as a threat to the favorable outcome of common infections in the community and hospital settings [19]. Staphylococcus aureus showed resistance due to the production of penicillinase with the ability to hydrolyzing penicillin, the first generation resistant due to beta-lactamases, and third-generation cephalosporin are resistant due to the production of extended-spectrum bête lactamases (ESBLS). Microorganisms are the enemies to mankind and cause very profound damage to the human body as well as other living organisms. The agents, which can kill the microbes or arrest the multiplication, are called the antimicrobial agent's drugs. There are a lot of antimicrobial drugs of which some are discovered or established [20] [21].

\section{Methods and Materials}

\subsection{Study Population}

A total number of 50 wound swab samples were collected from burn patients admitted in the burn and plastic surgery unit in Dhaka Medical College Hospital within (January 2015 to May 2015). Among them, 28 were male patients and 22 were female patients. Age groups were 12 years to 60 years. Degree of burn first degree 24 and second degree 26 were included in this study.

\subsection{Ethical Approval}

Before starting this research project ethical permission was obtained from the Project Director and an ethical review committee of the national institute of burn and plastic surgery in medical college hospital. Patient consents were obtained from the inpatient consent form. A questionnaire was filled up before collecting any patient sample.

\subsection{Samples Preparation}

Wound samples were aseptically collected 7 days after admission to the hospital. The sample was collected from the different sites of burn, especially from the chest, hands, and legs.

\subsection{Processing of Specimens}

The specimen was processed according to the guidelines for the laboratory diagnosis of pathogens. This includes macroscopic, microscopy, Gram's staining, culture, biochemical, and antimicrobial sensitivity testing. 


\subsection{Study Site/Site}

The study was conducted in the Department of Microbiology at Primeasia University, Bangladesh.

\subsection{Sample Collection Procedure}

At the first preparation of $0.9 \%$ sodium chloride solution, each test tube contains $5 \mathrm{ml}$ and then sterilized by autoclave. Surface swabs were collected from burn wounds after removal of the dressing and application of $70 \%$ ethanol for cleansing the wound surface. Using sterile cotton swabs an area of $4 \mathrm{~cm}^{2}$ where the degree of the burn was highest had been swabbed for each patient. After collection of samples were homogenized in $5 \mathrm{ml}$ sterile normal solution [22].

\subsection{Microbiological Study of Burn Wound Samples}

Plate culture method: all specimens were inoculated on 5\% Blood agar, MacConkey, Mannitol salt agar, and Cetrimide agar plates by spread plate method, under an aseptic condition in a laminar airflow cabinet. Then culture plates were incubated overnight at 37 degree $\mathrm{C}$ aerobically. Isolation of microorganisms by total viable count by using colony counter. Blood agar was used for isolation and identification of all kinds of bacteria, MacConkey agar was used for gram-negative bacteria (E. coli, Klebsiella spp., Proteus spp.). Mannitol salt agar for Staphylococcus spp. and Cetrimide agar for Pseudomonas spp. Then gram staining for gram-positive and gram-negative and microscopic examination for morphology, color, and shape.

\subsection{Confirmative Biochemical Study}

Identify the bacteria from isolated samples several biochemical tests were done such as catalase, oxidase, IMVIC, TSI test. Then identified bacterial spp was put into nutrient agar slant and subcultures at 37 degree $\mathrm{C}$ for 24 hours to perform antibiotic sensitivity test.

\subsection{Antibiogram Study of Burn Wound Samples}

The standard agar disc diffusion method known as the Kirby-Bauer method was applied to study of antibiogram. At first Muller Hinton agar plates were prepared. Before inoculation, the sterile swab stick was passed against the wall of the normal saline solution tube to drain out the excess fluid and moistened. By using sterile technique bacterial cultures were taken by sterile cotton swab stick and a uniform lawn of bacterial growth was prepared on Muller Hinton agar plates. Using sterile forceps, antibiotic discs were placed equally spread apart on the surface of the medium. 5 discs were used on each plate. The plate was incubated overnight at 37 degree $\mathrm{C}$ and the results were obtained no more than $24 \mathrm{~h}$ from incubation. The antimicrobial pattern was interpreted by the presence or absence of a clear zone around the antibiotic disc and the zone of inhibition was measured in mm by applying an ordinary ruler. 


\section{Results}

Prevalence of microorganisms in burn wound samples (Figure 1): Out of 50 samples, 45 were found to be hugely populated with bacterial load from 120 $500 \mathrm{CFU} /$ plate, among them almost all were found to harbor Pseudomonas spp. in the range of 130 - $430 \mathrm{CFU} /$ plate (Table 1 and Table 2). Growth and proliferation of $S$. aureus was observed in 44 samples ranges from 15 - $360 \mathrm{CFU} /$ plate. Among the enteric bacteria, Klebsiella spp. was found to prevail among 32 samples in the ranges of 5 - $30 \mathrm{CFU} /$ plate, and the comparative lower frequency was observed in the case of Proteus spp. in 23 samples and E. coli in 13 samples.

Table 1. Bacterial load (CFU/plate) in burn wound swabs.

\begin{tabular}{|c|c|c|c|c|c|c|c|}
\hline Samples & $\begin{array}{c}\text { Degree of } \\
\text { burning }\end{array}$ & $\begin{array}{c}\text { TVC } \\
(\mathrm{CFU})\end{array}$ & $\begin{array}{l}\text { P. aeruginosa } \\
\text { CFU/plate }\end{array}$ & $\begin{array}{l}\text { S. aureus } \\
\text { CFU/plate }\end{array}$ & $\begin{array}{c}K . s p p \\
\text { CFU/plate }\end{array}$ & $\begin{array}{l}\text { Proteus spp } \\
\text { CFU/plate }\end{array}$ & $\begin{array}{l}\text { E. coli } \\
\text { CFU }\end{array}$ \\
\hline 01 & $1^{\text {st }}$ & 200 & 75 & 80 & 20 & 15 & 10 \\
\hline 02 & $1^{\mathrm{st}}$ & 92 & 90 & 1 & 1 & 0 & 0 \\
\hline 03 & $2^{\text {nd }}$ & 450 & 90 & 360 & 0 & 0 & 0 \\
\hline 04 & $1^{\mathrm{st}}$ & 0 & 0 & 0 & 0 & 0 & 0 \\
\hline 05 & $1^{\mathrm{st}}$ & 176 & 56 & 100 & 10 & 6 & 4 \\
\hline 06 & $2^{\text {nd }}$ & 415 & 240 & 150 & 20 & 5 & 0 \\
\hline 07 & $2^{\text {nd }}$ & 535 & 310 & 220 & 5 & 0 & 0 \\
\hline 08 & $2^{\text {nd }}$ & 320 & 170 & 80 & 30 & 25 & 15 \\
\hline 09 & $2^{\text {nd }}$ & 226 & 150 & 0 & 26 & 20 & 30 \\
\hline 10 & $1^{\mathrm{st}}$ & 150 & 90 & 40 & 10 & 7 & 3 \\
\hline 11 & $1^{\text {st }}$ & 67 & 50 & 17 & 0 & 0 & 0 \\
\hline 12 & $1^{\mathrm{st}}$ & 80 & 60 & 15 & 5 & 0 & 0 \\
\hline 13 & $1^{\mathrm{st}}$ & 120 & 85 & 25 & 10 & 0 & 0 \\
\hline 14 & $1^{\mathrm{st}}$ & 230 & 130 & 90 & 5 & 5 & 0 \\
\hline 15 & $2^{\text {nd }}$ & 310 & 230 & 80 & 0 & 0 & 0 \\
\hline 16 & $2^{\text {nd }}$ & 300 & 130 & 170 & 0 & 0 & 0 \\
\hline 17 & $2^{\text {nd }}$ & 420 & 350 & 70 & 0 & 0 & 0 \\
\hline 18 & $2^{\text {nd }}$ & 500 & 430 & 70 & 0 & 0 & 0 \\
\hline 19 & $2^{\text {nd }}$ & 340 & 260 & 60 & 10 & 5 & 0 \\
\hline 20 & $1^{\text {st }}$ & 70 & 40 & 30 & 0 & 0 & 0 \\
\hline 21 & $2^{\text {nd }}$ & 430 & 260 & 120 & 20 & 10 & 10 \\
\hline
\end{tabular}

*TVC (total viable count). Among 50 samples $(1-28)$ were male patients and rest of the samples $(29-50)$ were female patients. All the experiments have been done three times and the results were reproducible. One representative data have been shown.

Table 2. Confirmative biochemical identification of the isolates.

\begin{tabular}{|c|c|c|c|c|c|c|c|c|c|c|}
\hline \multirow{2}{*}{$\begin{array}{l}\text { Pathogenic } \\
\text { organisms }\end{array}$} & \multirow{2}{*}{$\begin{array}{c}\text { Catalase } \\
\text { test }\end{array}$} & \multirow{2}{*}{$\begin{array}{l}\text { Oxidase } \\
\text { test }\end{array}$} & \multicolumn{4}{|c|}{ TSI test } & \multirow{2}{*}{$\begin{array}{c}\text { Indole } \\
\text { Production }\end{array}$} & \multirow{2}{*}{ MR test } & \multirow{2}{*}{ VP test } & \multirow{2}{*}{$\begin{array}{c}\text { Citrate } \\
\text { utilization test }\end{array}$} \\
\hline & & & slant & Butt & Gas & $\mathrm{H} 2 \mathrm{~S}$ & & & & \\
\hline P. aeruginosa & + & + & $\mathrm{R}$ & $\mathrm{R}$ & - & - & - & - & - & + \\
\hline$S$. aureus & + & - & $\mathrm{Y}$ & $\mathrm{Y}$ & - & - & - & + & + & - \\
\hline$K$. spp. & + & - & $\mathrm{Y}$ & $\mathrm{Y}$ & + & - & + & + & + & + \\
\hline Protus spp. & + & - & $\mathrm{Y}$ & $\mathrm{Y}$ & + & + & + & + & - & + \\
\hline E. coli & + & - & $\mathrm{Y}$ & $\mathrm{Y}$ & + & - & + & + & - & - \\
\hline
\end{tabular}

TSI = Triple Sugar Iron, $\mathrm{R}=$ Red (alkaline), $\mathrm{Y}=$ Yellow (acidic), MR = Methyl Red, VP = Voges Proskauer. 


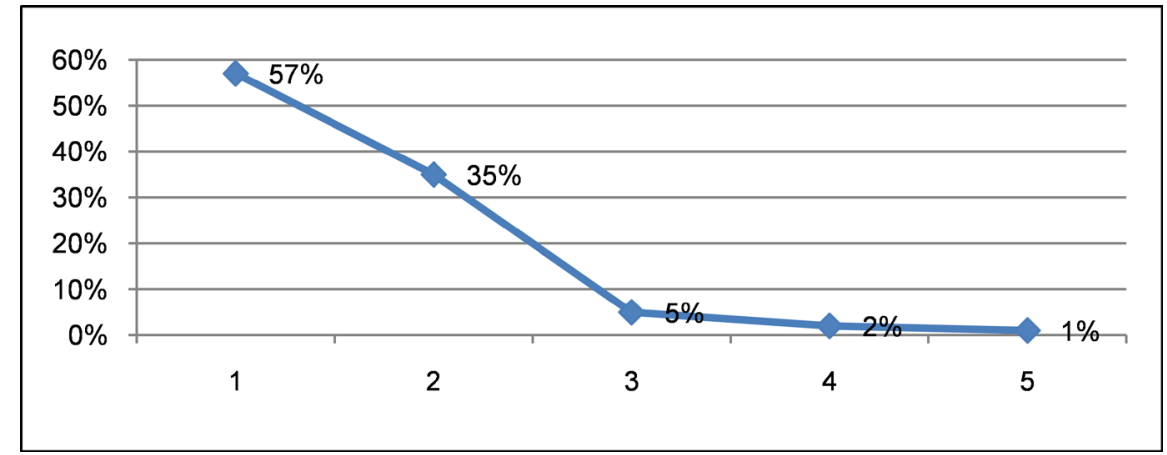

Figure 1. Percentage of isolated organisms from the collected samples: TVC $=11,641$. CFU/plate. 1. Pseudomonas. aeruginosa. $6636 \mathrm{CFU} /$ plate (57\%); 2. S. aureus. 4070 CFU/plate (35\%); 3. Klebsiella spp. $450 \mathrm{CFU} /$ plate (5\%); 4. Proteus spp. $243 \mathrm{CFU} /$ plate (2\%); 5. E. coli 152 CFU/plate (1\%).

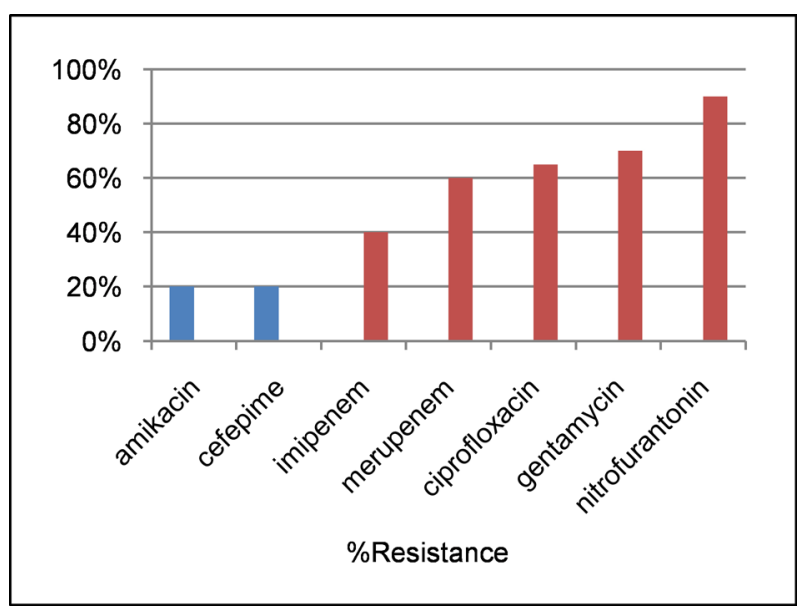

(a)

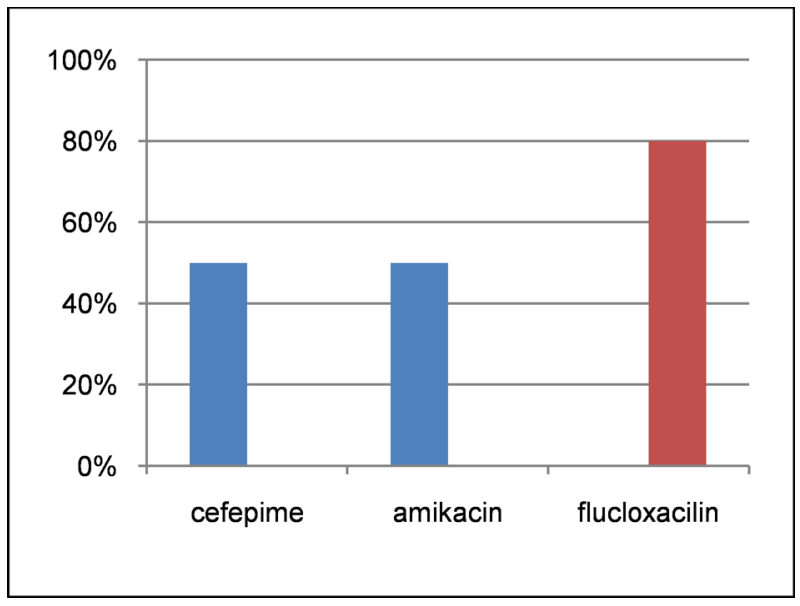

(c)

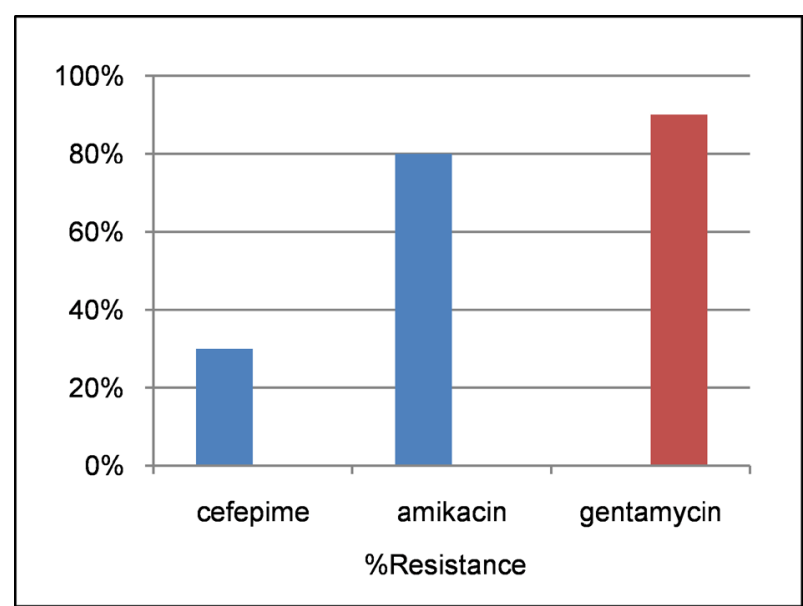

(b)

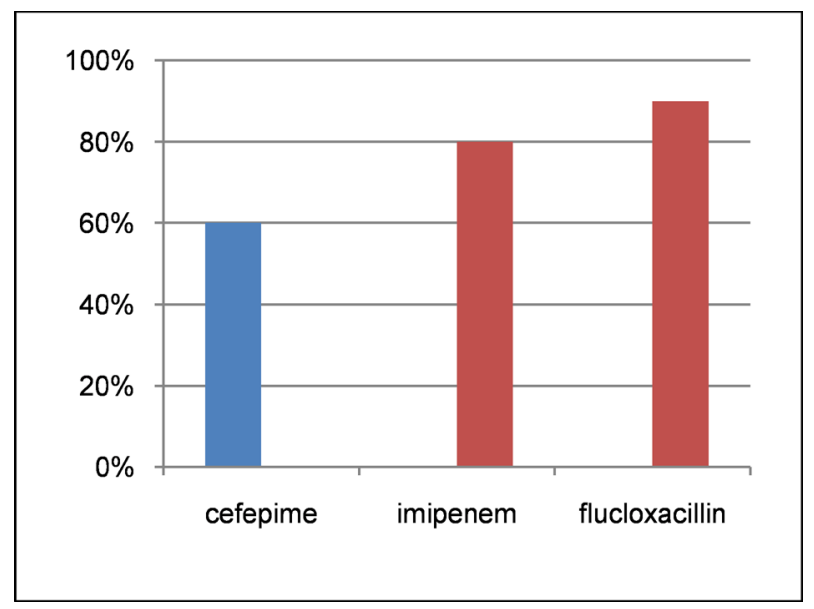

(d)

Figure 2. Antimicrobial \% of resistance pattern of Pseudomonas spp. (a), Staphylococcus aureus (b), E. coli (c), and Klebsiella spp. (d). against Ciprofloxacin (cip5), Amikacin (Ak30), Cefepime (CP30), Gentamycin (CN10), Nitrofurantonin (NF), Imipenem (IP10), Meropenem (MP), flucloxacillin (FX). The presented data were statistically analyzed by showing standard errors consider as $5 \%$. All experiments were carried out three times and 95\% accuracy was found. However, sensitivity of $\mathcal{S}$. aureus was scored towards imipenem (IP10) and meropenem (MR) and partially sensitive to flucloxacillin (FX). E. coli was found $100 \%$ sensitive to ciprofloxacin, and Klebsiella spp was found to be sensitive to amikacin (AK30) and gentamycin (CN10) respectively. 
Drug-resistance traits of the isolates: There are 8 common drug used, amikacin $(n=45,20 \%)$, cefepime $(n=45,20 \%)$, imipenem $(n=45,40 \%)$, merupenem $(\mathrm{n}=45,60 \%)$ ciprofloxacin $(\mathrm{n}=45,65 \%)$, gentamycin $(\mathrm{n}=45,70 \%)$, nitrofurantonin ( $\mathrm{n}=45,90 \%)$ were found to be ineffective against Pseudomonas spp. (Figure $2(\mathrm{a}))$, cefepime $(\mathrm{n}=44,30 \%)$, amikacin $(\mathrm{n}=44,80 \%)$, gentamycin $(\mathrm{n}=$ $44,90 \%$ ) were found to be ineffective against $S$. aureus. (Figure 2(b)), cefepime $(\mathrm{n}=13,50 \%)$, amikacin $(\mathrm{n}=13,50 \%)$, and flucloxacillin $(\mathrm{n}=13,80 \%)$ were found to be ineffective against $E$. coli isolates (Figure $2(\mathrm{c})$ ). Cefepime (n=23, $60 \%)$, imipenem $(n=23,80 \%)$, flucloxacillin $(n=23,90 \%)$, were found to be ineffective against Klebsiella spp. (Figure 2(d)).

\section{Discussion}

The prototype of bacterial resistance appears to be imperative for epidemiological study. It is worth noting that the multidrug-resistant isolates of Acinetobacter baumanni and $P$. aeruginosa are particular concern in burn care units. In our study, almost all the isolates exhibited the multi-drug resistance trait against commonly used antibiotics. However, an important clinical consideration has to be taken on the fact that since $E$. coli and Klebsiella pneumonia are well known to be the extended spectrum $\beta$-lactamase producers; these isolates found in our study may be further subjected for study [23] [24] and the prevalence of bacteria in 50 burn wound swabs was shown in the bacterial isolates were found in 45 (90\%) wound swab samples, and only 5 samples (10\%) were negative in bacterial growth. In this study the total viable count CFU/plate was found the highest amount in the second-degree burn patients. The results showed that Pseudomonas aeruginosa was common in all positive samples (57\%) followed by Staphylococcus aureus (35\%), Klebsiella spp. (5\%), Proteus spp. (2\%), and E. coli (1\%). All detected pathogens were Catalase positive and Oxidase negative but Pseudomonas spp. was Oxidase positive. Most of them were Indole, MR, VP test positive but Pseudomonas spp. was Indole, MR and VP negative, $S$ aureus Indole negative, Klebsiella was MR negative, Proteus, and E. coli VP negative. In Citrate Utilization Test all were positive except $S$. aureus and E. coli. In Triple Sugar Iron Agar Test all organisms were positive except Pseudomonas aeruginosa and $S$. aureus among them Proteus was unable to produce $\mathrm{H}_{2} \mathrm{~S}$. Pseudomonas and $S$. aureus were resistant to all antibiotics but $S$. aureus was sensitive to Imipenem and Meropenem and partially sensitive to flucloxacillin. E. coli were 100\% sensitive to ciprofloxacin, Klebsiella spp. were sensitive to Amikacin and. The pattern of bacterial resistance is important for epidemiological and clinical purposes [22] [25]. The results of the antimicrobial pattern give serious cause for concern because the predominant bacterial isolates were highly resistant to the commonly available antimicrobial agents [20] [26]. Our study revealed huge proliferation of bacteria in the burn wound samples studied, and traced a number of multi-drug resistant isolates despite the sex and degree of tissue damage of the patients. The results are in accordance with the contemporary studies and further implicate 
the necessity of stringent care in burn unit in hospitals. Routine monitoring of burn infections with antibiogram profile employing the primary experiments described here would be effective in delivering the detailed profile of burn wound prevailing microorganisms and hence would be implicative in context of overall public health management [21] [27] [28] [29] [30].

\section{Conclusion}

In conclusion, gram negative bacteria were the dominating bacteria all over the study period especially $P$. aeruginosa, most of which were multidrug resistant. Amikacin was the drug of choice for most gram negative bacteria and vancomycin was found to be effective against gram positive bacteria ( $S$. aureus and coagulase negative Staphylococci). Present investigation seems to be helpful in providing useful guidelines for choosing effective therapy against isolates from burn patients. Huge bacterial onset with an alarming threat of multidrug resistance would potentially raise the necessity of proper care and management of burn wound patients in hospital.

\section{Conflicts of Interest}

The authors declare no conflicts of interest regarding the publication of this paper.

\section{References}

[1] McManus, W.F., Goodwin, C.W., Mason Jr., A.D. and Pruitt Jr., B.A. (1981) Burn Wound Infection. The Journal of Trauma, 21, 753-756. https://doi.org/10.1097/00005373-198109000-00001

[2] Vindenes, H. and Bjerknes, R. (1995) Microbial Colonization of Large Wounds. Burns, 21, 575-579. https://doi.org/10.1016/0305-4179(95)00047-F

[3] Nasser, S., Mabrouk, A. and Maher, A. (2003) Colonization of Burn Wounds in Ain Shams University Burn Unit. Burns. 29, 229-333. https://doi.org/10.1016/S0305-4179(02)00285-1

[4] Pruitt Jr., B.A. and McManus, A.T. (1984) Opportunistic Infections in Severely Burned Patients. The American Journal of Medicine, 76, 146-154. https://doi.org/10.1016/0002-9343(84)90334-6

[5] MacMillan, B.G. (1980) Infections Following Burn Injury. Surgical Clinics of North America, 60, 185-196. https://doi.org/10.1016/S0039-6109(16)42043-8

[6] Lee, J.J., Marvin, J.A., Heimbach, D.M., Grube, B.J. and Engrav, L.H. (1990) Infection Control in a Burn Centre. Journal of Burn Care \& Rehabilitation, 11, 575-580.

[7] Zorgani, A., Zaidi, M., Ranka, R. and Shahen, A. (2002) The Pattern and Outcome of Septicemia in a Burn Intensive Care Unit. Annals of Burns and Fire Disasters, 15, 179-182.

[8] Ryan, C.M., Schoenfeld, D.A., Thorpe, W.P., Sheridan R.L. and Cassem E.H. (1998) Tompkins R.G. Objective Estimates of the Probability of Death from Burn Injuries. New England Journal of Medicine, 338, 362-366. https://doi.org/10.1056/NEJM199802053380604

[9] Hansbrough, J.F. (1987) Burn Wound Sepsis. Journal of Intensive Care Medicine, 2, 
313-327. https://doi.org/10.1177/088506668700200604

[10] Hussain, M.T., Karim, Q.N. and Tajuri, S. (1989) Analysis of Infection in a Burn Ward. Burns, 15, 229-302. https://doi.org/10.1016/0305-4179(89)90006-5

[11] McManus, A.T., Mason Jr., A.D., McManus, W.F. and Pruitt Jr., B.A. (1994) A Decade of Reduced Gram-Negative Infections and Mortality Associated with Improved Isolation of Burned Patients. Archives of Surgery, 129, 1306-1309. https://doi.org/10.1001/archsurg.1994.01420360096013

[12] Applegren, P., Bjornhagen, V., Bragderyd, K., Jonsson, C.E. and Ransjo, U. (2002) A Prospective Study of Infections in Burn Patients. Burns, 28, 38-46. https://doi.org/10.1016/S0305-4179(01)00070-5

[13] Lari, A.R. and Alaghehbandan, R. (2000) Nosocomial Infections in an Iranian Burn Care Centre. Burns, 26, 737-740. https://doi.org/10.1016/S0305-4179(00)00048-6

[14] Wurtz, R., Karajovic, M., Dacumos, E., Jovanovic, B. and Hanumadass, M. (1995) Nosocomial Infections in a Burn Intensive Care Unit. Burns, 21, 181-184. https://doi.org/10.1016/0305-4179(95)80005-9

[15] Kumar, A., Kashyap, B., Mishra, S., Agarwal, V. and Kaur, I.R. (2011) Bacteriological Analysis and Antibacterial Resistance Pattern in Burn Sepsis: An Observation at a Tertiary Care Hospital in East Delhi. Infectious Diseases in Clinical Practice, 19, 406-412. https://doi.org/10.1097/IPC.0b013e31822e9a33

[16] Bayat, A., Shaaban, H., Dodgson, A. and Dunn, K.W. (2003) Implications for Burns Unit Design Following Outbreak of Multi-Resistant Acinetobacter Infection in ICU and Burns Unit. Burns, 209, 303-306. https://doi.org/10.1016/S0305-4179(03)00011-1

[17] Shi, M.M., Zhao, D.M., Wang, Q., Cheng, J., Ma, T., Xu, Y.-H., et al. (2010) Analysis of Drug Resistance and Risk Factors of Enterobacteriaceae in Burn Units. Chinese Journal of Burns, 26, 199-201.

[18] Thompson, P.B., Herndon, D.N., Traber, D.L. and Abston, S. (1986) Effect on Mortality of Inhalation Injury. The Journal of Trauma, 26, 163-165.

https://doi.org/10.1097/00005373-198602000-00012

[19] Siegel, J.D., Rhinehart, E., Jackson, M., Chiarello, L. and Healthcare Infection Control Practices Advisory Committee (2007) Healthcare Infection Practices Committee. Management of Multidrug-Resistant Organisms in Health Care Settings 2006. American Journal of Infection Control, 35, S165-S193. https://doi.org/10.1016/j.ajic.2007.10.006

[20] Chan, M. (2012) Antimicrobial Resistance in the European Union and the World. Conference on Combating Antimicrobial Resistance: Time for Action, Copenhagen, March 2012, 20.

[21] Bang, R.L., Gang, R.K., Sanyal, S.C., Mokaddas, E.M. and Lari, A.R.A. (1999) Beta-Haemolytic Streptococcus Infection in Burns. Burns, 25, 242-246. https://doi.org/10.1016/S0305-4179(98)00167-3

[22] National Committee for Clinical Laboratory Standards (1993) Methods for Determining Bacterial Activity of Anti Microbial Agents, Tenative Guidelines, M26-T NCCLS. National Committee for Clinical Laboratory Standards Villanova.

[23] Raja, N.S. and Singh, N.N. (2007) Antimicrobial Susceptibility Pettern of Clinical Isolates of Pseudomonas aeruginosa in Tertiary Care Hospital. Journal of Microbiology, Immunology and Infection, 40, 45-49.

[24] Guggenheim, M., Zbinden, R., Handschin, A.E., Gohritz, A., Altintas, M.A. and Giovanoli, P. (2009) Changes in Bacterial Isolates from Burn Wound and Their An- 
tibiograms: A 20-Year Study (1986-2005). Burns, 35, 553-560. https://doi.org/10.1016/j.burns.2008.09.004

[25] Gosian, A. and Gamelli, R.L. (2005) A Primer in Cytokines. Journal of Burn Care \& Rehabilitation, 26, 7-12.

[26] Nasrabadi, B. and Hajia, M. (2012) Multidrug-Resistant $P$. aeruginosa Strains in Burn Center Hospital, Tehran, Iran. HealthMED Journal, 6, 403-406.

[27] Kehinde, A.O., Ademola, S.A., Okesola, A.O., Oluwatosin, O.M. and Bakare, R.A. (2004) Pattern of Bacterial Pathogens in Burn Wound Infections in Ibadan, Nigeria. Annals of Burns and Fire Disasters, 17, 12-15.

[28] Cook, N. (1998) Methicillin-Resistant Staphylococcus aureus versus the Burn Patient. Burns, 24, 91-98. https://doi.org/10.1016/S0305-4179(97)00114-9

[29] Taylor, G.D., Kibsey, P., Kirkland, T., Burroughs, E. and Tredget, E. (1992) Predominance of Staphylococcal Organisms in Infections Occurring in a Burns Intensive Care Unit. Burns, 18, 332-335. https://doi.org/10.1016/0305-4179(92)90158-Q

[30] Jonas, R.N. (2001) Resistance Pattern among Nosocomial Pathogens; Trends over the Past Few Years. Chest, 119, 397S-404S.

https://doi.org/10.1378/chest.119.2_suppl.397S 